\title{
BIRTH RELATED FACTORS DETERMINING RED BLOOD CELL TRANSFUSION AMONG SICK NEONATES
}

\author{
Mini Chellamma Viswanathan'1, Sajith Vilambil2, Kumari Krishnakumariamma Chakrapani Usha ${ }^{3}$ \\ ${ }^{1}$ Assistant Professor, Department of Transfusion Medicine, Government Medical College, Trivandrum, Kerala, India. \\ ${ }^{2}$ Associate Professor, Department of Transfusion Medicine, Government Medical College, Thrissur, Kerala, India. \\ ${ }^{3}$ Professor and HOD, Department of Transfusion Medicine, Sree Mookambika Institute of Medical Sciences, Kanyakumari, Tamilnadu, \\ India.
}

\begin{tabular}{l}
\hline ABSTRACT \\
BACKGROUND \\
Many of the neonates with low birth weight and gestational age require transfusion of red blood cells during their neonatal period. \\
This research is assessing factors and clinical conditions for red blood cell transfusions of low birth weight (LBW) infants. We \\
wanted to identify the birth related determinants of red blood cell transfusion in sick neonates.
\end{tabular}

\section{METHODS}

This was a case control study done in 300 neonates admitted to the Sri Avittom Thirunal Hospital (SATH), Government Medical College, Thiruvananthapuram. Cases were sick neonates who were transfused with red cells. The neonatal demographic and birth characteristics, details of the baby, indication for admission and transfusion, pre and post transfusion haematocrit, treatment given and outcome, complications occurring during delivery and post-natal complications also were analysed. All statistical data were analysed using SPSS software version 16.

\section{RESULTS}

On assessment of the age, mean age of the cases and controls were compared and there was no significance. $0+$ blood group was seen predominantly in the neonates who received transfusion. Mean birth weight was $1.8 \pm 04$ in both groups and there was no significant difference. Mean gestational age was $33.9 \pm 2.8$ in the case group and $33.5 \pm 2.7$ in the control group. Statistically significant difference was not there. On comparison, APGAR score was statistically significant. On comparing the diagnosis, the prevalence of congenital pneumonia, Small for Gestational Age (SGA) ( $p=0.002)$ and Neonatal Jaundice (NN) were found to be significantly higher in the case group. On assessing the intra natal complications, $78.7 \%$ of the mothers in the case group had intranatal complications compared to $61.3 \%$ in the control group. p Value was significant. Caesarean section was significantly more in the case group. $p$ value was significant in caesarean section and cord prolapse. Post-natal complications were significant in this study. The frequency of anaemia and cardiac diseases were significantly higher in the case group compared to the control group. When pre transfusion haematocrit was compared, mean haematocrit in the case group was $27.1 \pm 4.4$ compared to $54.1 \pm 6.3$ in the control group. This is statistically significant. On analysis, clinical sepsis was significantly higher in the transfused group.

\section{CONCLUSIONS}

After analysis it was found that APGAR score, presence of congenital pneumonia, SGA, neonatal jaundice, intra natal complications, caesarean section, cord prolapse, post-natal complications, frequency of anaemia and cardiac diseases, pre transfusion haematocrit and clinical sepsis were significantly more in the case group.

\section{KEY WORDS}

Neonate, Intra Natal, Haemorrhage, Low Birth Weight, Post Natal, Sepsis

HOW TO CITE THIS ARTICLE: Viswanathan MC, Vilambil S, Usha KKC. Birth related factors determining red blood cell transfusion among sick neonates. J. Evolution Med. Dent. Sci. 2019;8(27):2192-2196, DOI: 10.14260/jemds/2019/480

\section{BACKGROUND}

Majority of the neonates with low birth weight and gestational age require transfusion of red blood cells during their neonatal period. Most of these transfusions will be administered in the first postnatal month. Many aspects of haematopoiesis are either incompletely developed in preterm infants or are adapted to serve the foetus. This lack of development and/ or adaptation to extra uterine life

'Financial or Other Competing Interest': None.

Submission 14-05-2019, Peer Review 21-06-2019,

Acceptance 28-06-2019, Published 08-07-2019.

Corresponding Author:

Dr. Sajith Vilambil,

Associate Professor

Department of Transfusion Medicine,

Government Medical College,

Thrissur, Kerala, India.

E-mail: drsajithmenon@gmail.com

DOI: $10.14260 /$ jemds/2019/480 diminishes the capacity of the neonate to produce red cells, platelets and neutrophils particularly during the stress of lifethreatening illnesses encountered after pre term birth such as sepsis, severe pulmonary dysfunction, necrotising enterocolitis, and immune cytopenias.

The serious medical and surgical problems of preterm birth can be further complicated by phlebotomy losses, bleeding, haemolysis and consumptive coagulopathy. Preterm infants begin life with quantities of blood cells and clotting proteins that are barely adequate. These infants have a diminished ability to increase production adequately to compensate for the haematologic problems they experience. Preterm infants especially those with birth weight less than $1.5 \mathrm{~kg}$ and with respiratory distress are given numerous red cell transfusions early in life because of several interacting factors. Neonates delivered before 28 weeks of gestation are born before the bulk of iron transport has occurred from the mother to foetus before the onset of marked erythropoietic activity of foetal marrow. 


\begin{tabular}{|c|c|c|c|c|}
\hline \multirow{2}{*}{ Age in Days } & \multicolumn{2}{|c|}{ Case } & \multicolumn{2}{c|}{ Control } \\
\cline { 2 - 5 } & Number & Percent & Number & Percent \\
\hline $1-5$ & 127 & 84.7 & 133 & 88.7 \\
\hline $6-10$ & 19 & 12.7 & 17 & 11.3 \\
\hline$>10$ & 4 & 2.7 & 0 & 0.0 \\
\hline Mean \pm SD & \multicolumn{3}{|c|}{$3.5 \pm 3$} & \multicolumn{2}{c|}{$3.3 \pm 1.9$} \\
\hline \multicolumn{3}{|c|}{ Table 1. Comparison of Age in Days } \\
\hline$t=0.53, p=0.599$
\end{tabular}

\begin{tabular}{|c|c|c|c|c|c|c|}
\hline \multirow{2}{*}{ Sex } & \multicolumn{2}{|c|}{ Case } & \multicolumn{2}{c|}{ Control } & \multirow{2}{*}{$\mathcal{\chi}^{\mathbf{2}}$} & \multirow{2}{*}{} \\
\cline { 2 - 5 } & Number & Percent & Number & Percent & & \\
\hline Male & 79 & 52.7 & 75 & 50.0 & \multirow{2}{*}{0.21} & 0.644 \\
\hline Female & 71 & 47.3 & 75 & 50.0 & \\
\hline \multicolumn{7}{|c|}{ Table 2. Comparison of Sex } \\
\hline
\end{tabular}

\begin{tabular}{|c|c|c|c|c|c|c|}
\hline \multirow{2}{*}{$\begin{array}{l}\text { Blood } \\
\text { Group }\end{array}$} & \multicolumn{2}{|c|}{ Case } & \multicolumn{2}{|c|}{ Control } & \multirow{2}{*}{$\chi^{2}$} & \multirow[b]{2}{*}{$\mathbf{p}$} \\
\hline & Number & $\%$ & Number & $\%$ & & \\
\hline$A+v e$ & 37 & 24.7 & 49 & 32.7 & \multirow{7}{*}{8.01} & \multirow{7}{*}{0.237} \\
\hline$A-v e$ & 6 & 4.0 & 0 & 0.0 & & \\
\hline $\mathrm{B}+\mathrm{ve}$ & 26 & 17.3 & 24 & 16.0 & & \\
\hline B-ve & 5 & 3.3 & 4 & 2.7 & & \\
\hline$A B+v e$ & 6 & 4.0 & 5 & 3.3 & & \\
\hline $0+\mathrm{ve}$ & 59 & 39.3 & 58 & 38.7 & & \\
\hline $0-\mathrm{ve}$ & 11 & 7.3 & 10 & 6.7 & & \\
\hline \multicolumn{7}{|c|}{ Table 3. Comparison of Blood Group } \\
\hline
\end{tabular}

\begin{tabular}{|c|c|c|c|c|c|}
\hline Group & Mean & SD & N & t & p \\
\hline Case & 1.8 & 0.4 & 150 & \multirow{2}{*}{0.06} & 0.950 \\
\hline Control & 1.8 & 0.4 & 150 & \\
\hline \multicolumn{7}{|c|}{ Table 4. Comparison of Birth Weight } \\
\hline
\end{tabular}

\begin{tabular}{|c|c|c|c|c|}
\hline \multirow{2}{*}{$\begin{array}{c}\text { Gestational Age } \\
\text { in Weeks }\end{array}$} & \multicolumn{2}{|c|}{ Case } & \multicolumn{2}{c|}{ Control } \\
\cline { 2 - 5 } & Number & Percent & Number & Percent \\
\hline$<=30$ & 25 & 16.7 & 23 & 15.3 \\
\hline $31-35$ & 68 & 45.3 & 78 & 52.0 \\
\hline$>35$ & 57 & 38.0 & 49 & 32.7 \\
\hline Mean \pm SD & \multicolumn{3}{|c|}{$33.9 \pm 2.8$} & \multicolumn{2}{c|}{$33.5 \pm 2.7$} \\
\hline \multicolumn{4}{|c|}{ Table 5. Comparison of Gestational Age in Weeks } \\
\hline$t=1.21, p=0.227$
\end{tabular}

\begin{tabular}{|c|c|c|c|c|c|c|}
\hline \multirow{2}{*}{$\begin{array}{l}5 \text { Minute Apgar } \\
\text { Score }\end{array}$} & \multicolumn{2}{|c|}{ Case } & \multicolumn{2}{|c|}{ Control } & \multirow{2}{*}{$\chi^{2}$} & \multirow{2}{*}{$\mathbf{p}$} \\
\hline & Number & Percent & Number & Percent & & \\
\hline$<=5$ & 12 & 8.0 & 0 & 0.0 & & 0.000 \\
\hline$>5$ & 138 & 92.0 & 150 & 100.0 & $12.5^{* *}$ & 0.000 \\
\hline \multicolumn{7}{|c|}{ Table 6. Comparison of 5 Minutes APGAR Score } \\
\hline
\end{tabular}

\begin{tabular}{|c|c|c|c|c|c|c|}
\hline \multirow{2}{*}{ Diagnosis } & \multicolumn{2}{|c|}{ Case } & \multicolumn{2}{c|}{ Control } & \multirow{2}{*}{$\boldsymbol{\chi}^{\mathbf{2}}$} & \multirow{2}{*}{$\mathbf{p}$} \\
\cline { 2 - 7 } & Number & Percent & Number & Percent & 3.57 & 0.059 \\
\hline Preterm & 120 & 80.0 & 132 & 88.0 & 3.57 & 0.906 \\
\hline Low birth weight & 89 & 59.3 & 90 & 60.0 & 0.01 & 0.01 \\
\hline Sepsis & 22 & 14.7 & 15 & 10.0 & 1.51 & 0.219 \\
\hline SGA & 55 & 36.7 & 31 & 20.7 & $9.39^{* *}$ & 0.002 \\
\hline Cong.Pneumonia & 23 & 15.3 & 6 & 4.0 & $11.03^{* *}$ & 0.001 \\
\hline Meningitis & 2 & 1.3 & 4 & 2.7 & 0.68 & 0.409 \\
\hline GI bleed & 14 & 9.3 & 6 & 4.0 & 3.43 & 0.064 \\
\hline Seizures & 9 & 6.0 & 13 & 8.7 & 0.78 & 0.376 \\
\hline NNJ & 23 & 15.3 & 5 & 3.3 & $12.76^{* *}$ & 0.000 \\
\hline \multicolumn{7}{|c|}{ Table 7. Comparison of Diagnosis } \\
\hline **: - Significant at 0.01 level.
\end{tabular}

\begin{tabular}{|c|c|c|c|c|c|c|}
\hline $\begin{array}{c}\text { Intra natal } \\
\text { Complications }\end{array}$ & \multicolumn{2}{|c|}{ Case } & \multicolumn{2}{c|}{ Control } & \multirow{2}{*}{$\chi^{2}$} & p \\
\cline { 2 - 5 } & Number & Percent & Number & Percent & & \\
\hline Normal & 32 & 21.3 & 58 & 38.7 & \multirow{2}{*}{$10.73^{* *}$} & \multirow{2}{*}{0.001} \\
\hline Abnormal & 118 & 78.7 & 92 & 61.3 & \\
\hline \multicolumn{7}{|c|}{ Table 8. Comparison of Intra Natal Complications } \\
\hline
\end{tabular}

\begin{tabular}{|c|c|c|c|c|c|c|c|}
\hline \multirow{2}{*}{\multicolumn{2}{|c|}{$\begin{array}{c}\text { Intra Natal } \\
\text { Complications }\end{array}$}} & \multicolumn{2}{|c|}{ Case } & \multicolumn{2}{|c|}{ Control } & \multirow{2}{*}{$\chi^{2}$} & \multirow{2}{*}{ p } \\
\hline & & Numbe & Percent & Numbe & Percent & & \\
\hline \multirow{2}{*}{ CS } & No & \begin{tabular}{|l|}
86 \\
\end{tabular} & $\begin{array}{l}57.3 \\
\end{array}$ & \begin{tabular}{|l|}
103 \\
17
\end{tabular} & \begin{tabular}{|l|}
68.7 \\
21.2
\end{tabular} & \multirow[t]{2}{*}{ 4.13* } & \multirow[t]{2}{*}{0.042} \\
\hline & Yes & 64 & 42.7 & 47 & 31.3 & & \\
\hline \multirow[b]{2}{*}{ APH } & No & 143 & 95.3 & 148 & 98.7 & \multirow[b]{2}{*}{2.86} & \multirow{2}{*}{0.091} \\
\hline & Yes & 7 & 4.7 & 2 & 1.3 & & \\
\hline \multirow{2}{*}{$\begin{array}{l}\text { Assisted } \\
\text { Delivery }\end{array}$} & No & 132 & 88.0 & 126 & 84.0 & & \multirow{2}{*}{0.318} \\
\hline & Yes & & & & 16.0 & & \\
\hline \multirow{2}{*}{ Haemorrhage } & No & 131 & 87.3 & 134 & 89.3 & \multirow{2}{*}{0.29} & \multirow{2}{*}{0.590} \\
\hline & Yes & 1 & & & & & \\
\hline \multirow{2}{*}{ Cord Prolapse } & No & 146 & 97.3 & 150 & 100.0 & \multirow{2}{*}{$4.05 *$} & \multirow{2}{*}{0.044} \\
\hline & Yes & 4 & 2.7 & 0 & 0.0 & & \\
\hline Difficult & No & 144 & 96.0 & 147 & 98.0 & 1.03 & 0.310 \\
\hline
\end{tabular}

\begin{tabular}{|c|c|c|c|c|c|c|}
\hline delivery & Yes & 6 & 4.0 & 3 & .0 & \\
\hline \multicolumn{7}{|c|}{ Table 9. Comparison of Intra Natal Complications } \\
\hline \multicolumn{7}{|c|}{ *: - Significant at 0.05 level } \\
\hline \multirow{2}{*}{$\begin{array}{c}\text { Post Natal } \\
\text { Complications }\end{array}$} & \multicolumn{2}{|c|}{\begin{tabular}{|c|} 
Case \\
\end{tabular}} & \multicolumn{2}{|c|}{\begin{tabular}{|l|} 
Control \\
\end{tabular}} & \multirow{2}{*}{$\chi^{2}$} & \multirow[b]{2}{*}{ p } \\
\hline & Numbe & Percent & Number & Percent & & \\
\hline Normal & 45 & 30.0 & 73 & 48.7 & \multirow{2}{*}{$10.95^{* *}$} & \multirow{2}{*}{0.001} \\
\hline Abnormal & 105 & 70.0 & 77 & 51.3 & & \\
\hline \multicolumn{7}{|c|}{ Table 10. Comparison of Post Natal Complications in Different Groups } \\
\hline **: - Significant at 0. & 01 level & & & & & \\
\hline
\end{tabular}

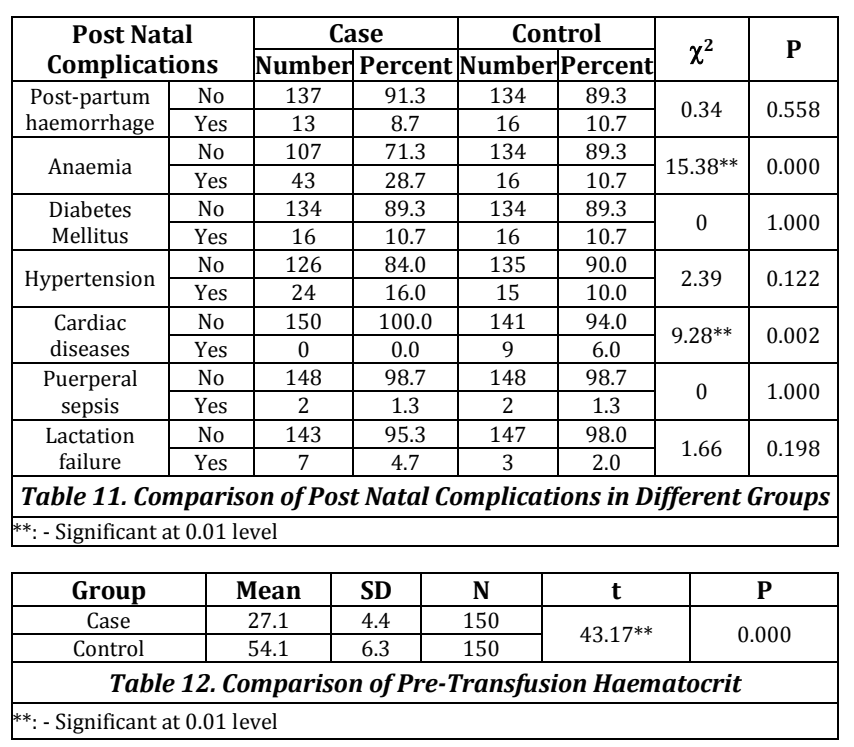

\begin{tabular}{|c|c|c|c|c|c|c|}
\hline \multirow{2}{*}{$\begin{array}{c}\text { Clinical } \\
\text { Sepsis }\end{array}$} & \multicolumn{2}{|c|}{ Case } & \multicolumn{2}{c|}{ Control } & \multirow{2}{*}{$\chi^{2}$} & \multirow{2}{*}{$\mathbf{P}$} \\
\cline { 2 - 5 } & Number & Percent & Number & Percent & & \\
\hline Yes & 83 & 55.3 & 40 & 26.7 & \multirow{2}{*}{$25.48^{* *}$} & \multirow{2}{*}{0.000} \\
\hline No & 67 & 44.7 & 110 & 73.3 & \\
\hline \multicolumn{7}{|c|}{ Table 13. Comparison of Clinical Sepsis } \\
\hline Odds = 3.41 (2.10 - 5.53)
\end{tabular}

Several diseases during neonatal period require repeated blood sampling leading to iatrogenic anaemia. Preterm infants are unable to mount an effective erythropoietin response.

An important reason for the lower haemoglobin values of preterm infant than those of term infants is that preterm infants have a relatively diminished erythropoietin plasma level in response to anaemia. The major physiological impact of anaemia of prematurity is decreased oxygen delivery to the tissues which result in compensatory responses like increase in heart rate, cardiac output and cerebral blood flow, poor growth, decrease in activity etc. Low RBC mass contributes to tachypnoea, dyspnoea, apnoea, tachycardia, bradycardia, feeding difficulties and lethargy and these problems can be alleviated by PRC transfusions. Since red blood cell transfusion remains the primary treatment of anaemia in the neonatal period, the basis of PRC transfusion is discussed in this review.

We reasoned that assessing risk factors and clinical conditions before the first transfusion will improve our ability to estimate the need for red blood cell (RBC) transfusions of low birth weight (LBW) infants. Such estimation can identify infants who require more number of RBC transfusions. Minimising the number of units of RBC transfusion will decrease donor exposure. Risk based estimation of blood usage can identify those infants who are likely to require only one/more transfusion. This helps to identify unnecessary transfusions also. 


\section{METHODS}

This was a case control study done in 300 neonates. Sample population were newborn babies with gestational age less than 37 weeks and/or birth weight less than 2500 grams admitted to the Neonatal Intensive Care Unit (NICU) of Sri Avittom Thirunal Hospital (SATH), Government Medical College Thiruvananthapuram. SATH has a level III NICU caring for both in-born and out-born infants.

Study was done for a period of one and a half years in the Department of Transfusion Medicine, Government Medical College Thiruvananthapuram.

Cases were sick neonates admitted to the NICU who were transfused with packed red cells at least once during their hospital stay. Controls are sick neonates who did not receive packed cells. Infants with chromosomal abnormalities, congenital heart disease, other life-threatening congenital abnormalities, death within first 24 hours were excluded from the study.

Case records of sick neonates admitted in NICU of SATH for a period of one and a half years were studied. The neonatal demographic and birth characteristics known to be associated with anaemia of prematurity were recorded. The details of the baby such as age, sex, birth weight, gestational age, blood group, 5 minutes APGAR score, indication for admission in NICU, diagnosis, indication for packed red cell (PRC) transfusion, pre transfusion haematocrit, post transfusion haematocrit, presence of clinical sepsis, type of antibiotics given and outcome of the baby were recorded. Complications occurring during delivery like cord prolapse, assisted delivery, difficult delivery, haemorrhage or caesarean section etc. were recorded. Post-natal complications were also considered which included puerperal sepsis and lactation failure.

\section{Ethics}

The study was approved by the human ethical and research committee, Government Medical College Thiruvananthapuram. The parents of the study subjects were counselled about the nature of the study. A written consent was obtained from the parents of the newborns included in the study.

\section{Statistics}

All statistical data were analysed using SPSS software version 16. Continuous variables were expressed as mean +/standard deviation. And qualitative data expressed as percentage. Independent $t$ test was used for comparing quantitative data between two groups. Categorical variables were compared using $\chi^{2}$ test. The predictive variables were calculated by univariate analysis.

\section{RESULTS}

Our study was a case control study done in 300 neonates admitted in the NICU of Sri Avittom Thirunal Hospital, Government Medical College, Thiruvananthapuram. Study subjects were divided into cases $(n=150)$ and controls $(n=150)$. Birth related details of both groups were studied and analysed.

On assessment of the age in days of the transfused neonates, $84.7 \%$ were in the age group of $1-5$ days, $12.7 \%$ were in the age group of 6-10 days and $2.7 \%$ were in the age group of more than 10 days. Mean age of the cases and controls were compared using independent $t$ tests. There was no significant difference between case and control groups.

On analysis of the sex, $52.7 \%$ of the transfused group was males and $47.3 \%$ was females. The control group had equal distribution of males and females. There was no significant difference between the two groups in this study.

While blood groups were analysed, $0+$ Blood group was seen predominantly in the neonates who received transfusion. In the total number of study subjects $\mathrm{O}+$ blood group had the highest frequency followed in order by $\mathrm{A}+, \mathrm{B}+$, O-, AB+ and B -. Neonates with $\mathrm{AB}$ - blood group were lacking in the study group. Analysis did not show any statistical significance.

Birth weights of case and control groups were compared by independent t test. Mean birth weight was $1.8 \pm 04$ in both groups. There was no significant difference between the two groups. On analysing the gestational age of the neonates in weeks, $16.7 \%$ of the case group and $15.3 \%$ of the control group belonged to $<30$ weeks. Mean gestational age was 33.9 \pm 2.8 in the case group and $33.5 \pm 2.7$ in the control group. Statistically significant difference was not found between the two groups. On assessment, neonates with $<=5$ minutes APGAR score was $8 \%$ in the case group compared to $0 \%$ in the control group. This observation was statistically significant. $(\mathrm{P}$ value $=0.000)$

$80 \%$ were pre term (PT) infants and $59.3 \%$ were low birth weight (LBW) infants in the case group. 9.3\% of neonates had gastro intestinal bleed, $6 \%$ had seizures and $1.3 \%$ had meningitis. On comparing the diagnosis, the prevalence of congenital pneumonia, $(p=0.001)$ Small for Gestational Age (SGA) $(\mathrm{P}=0.002)$ and Neonatal Jaundice $(\mathrm{NNJ})$ $(\mathrm{P}=0.000)$ were found to be significantly higher in the case group. In the control group, $88 \%$ were PT infants, $60 \%$ LBW and $20.7 \%$ small for gestational age (SGA). $10 \%$ of the control group had sepsis, $2.7 \%$ had meningitis. $8.7 \%$ had seizures $4 \%$ had GI bleed and 3.3\% had neonatal jaundice.

On assessing the intra natal complications, $78.7 \%$ of the mothers in the case group had intra natal complications compared to $61.3 \%$ in the control group. $p$ value was significant. On assessment of intra natal complications in case group, caesarean section done in $42.7 \%$, ante partum haemorrhage in $4.7 \%$, assisted delivery in $12 \%$, haemorrhage in $12.7 \%$, cord prolapse in $2.7 \%$, difficult delivery in $4 \%$. The control group revealed caesarean section in $31.3 \%$, ante partum haemorrhage in $1.3 \%$, assisted delivery in $16 \%$, haemorrhage in $10.7 \%$ and difficult delivery in $2 \%$. Caesarean section was significantly more in the case group. $p$ value was significant in caesarean section and cord prolapse.

Post-natal complications were significant in this study and $\mathrm{p}$ value was 0.001 . On assessment of post-natal complications of the case group, $28.7 \%$ had anaemia, $16 \%$ had hypertension, $10.7 \%$ had diabetes, $8.7 \%$ had postpartum haemorrhage, $4.7 \%$ had lactation failure and $1.3 \%$ had puerperal sepsis. In the control group $10.7 \%$ had anaemia, $10 \%$ had hypertension, $10.7 \%$ had diabetes, $10.7 \%$ had postpartum haemorrhage, $2 \%$ had lactation failure and $1.3 \%$ had puerperal sepsis. The frequency of anaemia and cardiac diseases were significantly higher in the case group compared to the control group. $\mathrm{P}$ value was found to be 0.000 and 0.002 respectively.

When pre transfusion haematocrit was compared mean haematocrit in the case group was $27.1 \pm 4.4$ compared to 
$54.1 \pm 6.3$ in the control group. This is statistically significant, and the $p$ value was 0.000 .

On analysis, clinical sepsis was detected in $55.3 \%$ of the case group and only in $26.7 \%$ of the control group. Clinical sepsis was significantly higher in the transfused group with $p$ value 0.000 . When outcome was analysed, no deaths reported in the case and control groups.

\section{DISCUSSION}

In our study, neonates who had received transfusions were included in the case group and those who had not received transfusions were included in the control group. Our study compared the demographic characteristics and variables which are known to be associated with transfusion of packed red cells in neonates.

Analysis of neonatal data of case group showed that $84 \%$ belonged to the age group 1-5 days, $12.7 \%$ to the age group of 6-10 days and only $4 \%$ to the age group of more than 10 days. The mean age at which transfusions were given was 3.5 \pm 3 days. According to a multicenter study in 8 NICUs of Brazilian Neonatal Research Network, the number of transfusions was higher during the first 28 days of life compared to that after 28 days of life. The number of transfusions was less after 28 days till discharge. ${ }^{1}$

In our study, male to female ratio was similar in the case and control groups. Blood group analysis showed that the percentage of $0+$ group was more in the transfused group, but statistical significance was not observed. Comparison of the birth weight did not show any significant differences between the case and control groups. This finding correlated with the study by David A Paul et al. Analysis revealed that the mean gestational age of the neonates who received transfusion was $33.9 \pm 2.8$ days. We could not prove any definite association between low gestational age and transfusion requirements. Brown M.S et al postulated that the best predictor of blood transfusion was gestational age less than 30 weeks. $^{2}$ Jorge Fabres and Gay Wehrli had similar findings where the median gestational age was 26 weeks ${ }^{3}$. In a study to find out the risk factors for transfusion, Zuppa et al could prove that the gestational age is an important factor in deciding RBC transfusion in neonates. ${ }^{4}$ Five minutes APGAR score was a significant factor in deciding the transfusions to the neonates in our study. $8 \%$ of our case group had APGAR $<=5$ while such a low APGAR score was not found in the control group. Various observational studies and randomized controlled trials are in favour of this observation. ${ }^{5-7}$ We compared the diagnosis of the transfused and non-transfused group. This revealed that the frequency of congenital pneumonia (15.3\%) and neonatal jaundice (8.3\%) were significantly higher in the transfused group. Another significant observation in our study was the lower pre transfusion haematocrit value in the transfused group (27.1 \pm 4.4). This finding correlated with a study by Rachana Singh et al where they postulated that a low pre transfusion haematocrit associated with a higher number of RBC transfusions. ${ }^{8}$ Gomella in his study revealed that severe anaemia with haematocrit less than $25 \%$ was a definite indication for RBC transfusion. ${ }^{9-10}$

Clinical sepsis was found to be significantly higher in the transfused group. Sepsis was present in $55.3 \%$ of neonates in the case group compared to $26.7 \%$ in the control group. Other studies also point to such a situation. ${ }^{5}$ The clinical variables assessed in the infant's early hospital course may be used to predict the number of transfusions to be given, interventional strategies and counseling of parents.

Horbar et al opined that presence of anaemia, cardiac disease, severe critical illness, multiple organ dysfunction syndrome are the most significant determinants of red cell transfusions. ${ }^{11}$

Bishara N, Ohlis R.K and co-workers noted that Extremely Low Birth Weight (ELBW) infants develop anaemia of prematurity due to frequent blood draws as part of their care in NICUs. ${ }^{11}$ Kasat K, Hendricks and co-workers conducted a study at Cohen Child Medical Centre New York and postulated that tachycardia was the most sensitive predictor of benefit from PRC transfusions. ${ }^{12}$ Strauss R.G. Mock DM considered circulating red cell volume/mass as a decisive factor for transfusion rather than haemoglobin or haematocrit.

On comparing the postnatal complications of the case and control groups, the frequency of maternal anaemia was found to be $28.7 \%$ and $10.7 \%$ respectively. This is significantly higher in the case group.

Fabres et al. found that $85 \%$ of preterm received red blood cell transfusion and it was associated with birth weight, gestational age, age at first transfusion. ${ }^{13}$ Mimica et al. found that number of transfusions was associated with birth weight. ${ }^{14}$

In a study by Amelia et al it was found out that the following factors were associated with indications for transfusions: lower gestational age, higher SNAPPE II score, presence of apnoea, pulmonary haemorrhage, clinical sepsis, moderate/severe intraventricular haemorrhage, necrotizing enterocolitis, bronchopulmonary dysplasia, umbilical catheter use, parenteral nutrition, prolonged hospital stay. Same study narrates that premature newborns who received RBC transfusions during hospital stay had a 3.8- fold greater chance of developing enterocolitis and a $64 \%$ greater chance of also having a diagnosis of grade III to IV haemorrhage in comparison to those who did not receive transfusions. However, it was not possible to establish the temporal relationship between the transfusions and these complications. These variables were closely interrelated and, to some extent, reflect the morbidities and procedures often described for very-low-birth-weight newborns. (Amelia15)

In a retrospective study of premature infants with periintraventricular haemorrhage, progression of disease was found after RBC transfusions. The factors associated with the progression were gestational age and transfusion. ${ }^{16}$ In a meta-analysis that included Mohamed and Shah found an association between RBC transfusion and the occurrence of necrotizing enterocolitis. ${ }^{17}$ Del Vecchio et al. found an association between the reduction of transfusion rates and a lower incidence of bronchopulmonary dysplasia, retinopathy of prematurity and necrotizing enterocolitis.

\section{CONCLUSIONS}

After analysis it was found that APGAR score, presence of congenital pneumonia, SGA, neonatal jaundice, intra-natal complications, caesarean section, cord prolapse, post-natal complications, frequency of anaemia and cardiac diseases, pre-transfusion haematocrit and clinical sepsis were significantly more in the case group. 


\section{ACKNOWLEDGEMENT}

We thank Dr. K. C. Usha, Professor and HOD, Department of Transfusion Medicine, Sree Mookambika Institute of Medical Sciences, Kulasekharam, Kanyakumari, Tamilnadu, Dr Lalitha Kailas, Professor and HOD in Dept. of Paediatrics, Gokulam Medical College, Trivandrum, and Dr. Shobha Kumar, Professor in Dept. of Paediatrics, Govt. Medical College Trivandrum, for their scholarly guidance in the course of this work.

\section{REFERENCES}

[1] Santos D, Amelia MN, Gunsberg R, et al. Almedia for the Brazilian network on national research. Transfus 2010;(50).

[2] Bifano EM, Smith F, Borer J. Relationship between determinants of oxygen delivery and respiratory abnormalities in Preterm infants with anaemia. J Paeditrics 2002:p. 192-223.

[3] Franz AR, Pohlandt F. RBC transfusions in ELBW infants under restrictive transfusion guidelines: Is exogenous EPO necessary? Arch Dis Child Foetal Neonatal Ed 2001;84(2):F96-F100.

[4] Zuppa AA, Mazzotta M, Maragleano G, et al. Anaemia of prematurity: risk factors influencing $\mathrm{RBC}$ transfusions. Minerva Pediatric 1995;47(1-2):13-8.

[5] Bednarck FJ, Weisberger S, Richardson DK. Variations in BT among NP ICUs. SNAP 2 study group. J Paediatr 1998;133(5):601-7.

[6] Maier RF, Sonntag J, Walka MM, et al. Changing practices of RBC transfusion in infants with birth weights less than 1000 grams. J Paediatr 2000;136(2):220-4.

[7] Malek A, Sager R, Eckardt KU, et al. Lack of transport of EPO across the human placenta as studied by an in vitro perfusion system. Pflugers Arch 1994;427(12):157-61.
[8] Singh R, Visintainer PF, Frans ED. Association of NEC with anaemia and PRC transfusion in PT infants. J Perinatology 2004: p. 159-76.

[9] Mock DM, Bell EF, Lankford GL, et al. Hematocrit correlates well with circulating RBC volume in VLBW infants. Pediatr Res 2001;50(4):525-31.

[10] Horbar JD, Badger GJ, Carpenter JH, et al. Trends in mortality and morbidity for VLBW infants 1991-1999. Paediatrics 2002;110(1 Pt 1):143-51.

[11] Bishara N, Ohlis RK. The physiologic impact of anaemia in the neonate University of New Mexico; school of medicine, Albuqerque, USA. Clin Perinatology 1995;22:436-42.

[12] Kasat K, Hendricks-Munoz KD, Mally PV. Neonatal red blood cell transfusions: searching for better guidelines. Blood Transfusion 2011;9(1):86-94.

[13] Fabres J, Wehrli G, Marques MB, et al. Estimating blood needs for very-low-birth-weight infants. Transfusion 2006;46(11):1915-20.

[14] Mimica AF, dos Santos AM, da Cunha DH, et al. A very strict guideline reduces the number of erythrocyte transfusions in preterm infants. Vox Sang 2008;95(2):106-11.

[15] Baer VL, Lambert DK, Henry E, et al. Red blood cell transfusion of preterm neonates with a Grade 1 intraventricular hemorrhage is associated with extension to a grade 3 or 4 hemorrhage. Transfusion 2011;51(9):1933-9.

[16] Mohamed A, Shah PS. Transfusion associated necrotizing enterocolitis: a meta-analysis of observational data. Pediatrics 2012;129(3):529-40.

[17] Del Vecchio A, Henry E, D'Amato G, et al. Instituting a program to reduce the erythrocyte transfusion rate was accompanied by reductions in the incidence of bronchopulmonary dysplasia, retinopathy of prematurity and necrotizing enterocolitis. J Matern Fetal Neonatal Med 2013;26(Suppl 2):77-9. 